\title{
Sex Pheromone of the Scarab Beetle Phyllophaga (Phytalus) georgiana (Horn)
}

\author{
Paul S. Robbins • Satoshi Nojima • Sridhar Polavarapu • \\ Albrecht M. Koppenhöfer • Cesar Rodriguez-Saona • \\ Robert J. Holderaft • Nancy H. Consolie • \\ Daniel C. Peck • Wendell L. Roelofs
}

Received: 24 September 2008 /Revised: 12 November 2008 /Accepted: 31 December 2008 /Published online: 27 February 2009

(C) Springer Science + Business Media, LLC 2009

\begin{abstract}
The sex pheromone of Phyllophaga (Phytalus) georgiana was characterized as valine methyl ester, tentatively the L-enantiomer. This is the first sex pheromone identified from the Phyllophaga subgenus Phytalus. The pheromone was extracted from female glands, the active component isolated by coupled gas chromatographyelectroantennogram detection analysis, characterized by mass spectrometry, and shown to be active in field tests. The seasonal flight pattern was determined for P. georgiana as well as for three other species, $P$. anxia (both northern and southern genitalic forms), P. gracilis, and P. postrema.
\end{abstract}

Sridhar Polavarapu, deceased May 7, 2004. We dedicate this publication to our friend and colleague.

P. S. Robbins $(\bowtie) \cdot$ S. Nojima $\cdot$ D. C. Peck $\cdot$ W. L. Roelofs

Department of Entomology,

New York State Agricultural Experiment Station,

Cornell University,

Geneva, NY 14456, USA

e-mail: psr1@cornell.edu

S. Nojima

Department of Entomology, North Carolina State University, Raleigh, NC 27695, USA

S. Polavarapu $\cdot$ C. Rodriguez-Saona $\cdot$ R. J. Holdcraft Philip E. Marucci Center for Blueberry and Cranberry Research and Extension, New Jersey Agricultural Experiment Station,

Rutgers University,

Chatsworth, NJ 08019, USA

\section{A. M. Koppenhöfer}

Department of Entomology, Rutgers University,

New Brunswick, NJ 08901, USA

N. H. Consolie

Grape Genetics Research Unit, USDA-ARS,

Geneva, NY 14456, USA
The latter three species were captured in traps baited with Lisoleucine methyl ester.

Keywords L-Valine methyl ester-L-Isoleucine methyl ester Scarabaeidae $\cdot$ Melolonthinae $\cdot$ Cranberries

\section{Introduction}

The scarab beetle, Phyllophaga (Phytalus) georgiana, is distributed along the east coast of the United States from New Jersey to South Carolina, Georgia, Alabama, and Mississippi (Harpootlian 2001; Robbins et al. 2006). It is one of eight US species in the Phyllophaga subgenus Phytalus. The remaining Phytalus species (ca. 90) are distributed from Mexico, through Central America, to Brazil, Uruguay, and Paraguay (Evans and Smith 2007).

The larvae of $P$. georgiana are root-feeding pests of cranberries in New Jersey (Koppenhöfer et al. 2008). When the larvae were originally discovered feeding in the roots of cranberries, the species could not be identified because character differences in the larvae have yet to be described, although this is currently underway. To identify the species, ca. 50 larvae were reared to adulthood. The resulting adults were all identified as $P$. georgiana. We used these adults for the isolation and identification of the pheromone.

\section{Materials and Methods}

Pheromone Collections Larvae were dug from a bog in southern New Jersey and kept individually, in 30-ml plastic cups in a 3:1 mixture of greenhouse sand and screened peat moss raised to $12 \%$ moisture $(w / w)$, in a controlled environment room, at $25^{\circ} \mathrm{C}$ for the 16 -h photophase and 
$20^{\circ} \mathrm{C}$ for the 8-h scotophase. After eclosion, adult females were placed in observation cages to observe calling [abdominal pheromone gland everted (Leal et al. 1993; Nojima et al. 2003b)] during the scotophase. Once a female was observed calling, it was removed from the cage and its pheromone gland everted by applying gentle pressure to the abdomen. The gland was excised with scissors and extracted for $20 \mathrm{~min}$ in $200 \mu \mathrm{l}$ of dichloromethane. After this, the gland was removed from the solvent and the extract was concentrated under a nitrogen stream to a volume of ca. $20 \mu \mathrm{l}$. Samples were stored at $-80^{\circ} \mathrm{C}$ until analyzed.

Gas Chromatograph-Electroantennogram Detection Analysis Extracts of single glands were analyzed with a coupled gas chromatograph-electroantennogram detector (GC-EAD) system. A Hewlett Packard 5890 series II gas chromatograph, equipped with either a non-polar SPB-1 capillary column $(30 \mathrm{~m} \times 0.25 \mathrm{~mm}$ ID, $0.25 \mu \mathrm{m}$ film thickness; Supelco, Bellefonte, PA, USA) or a polar EC-

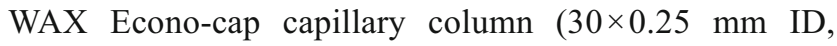
$0.25 \mu \mathrm{m}$ film thickness; Alltech, Deerfield, IL, USA), was used for the GC-EAD analyses. The carrier gas was $\mathrm{N}_{2}$ at a

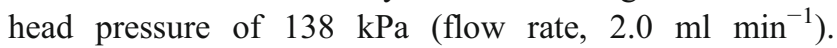
Injections were made in the splitless mode (split valve opened at $1 \mathrm{~min}$ ). The temperature program was $40^{\circ} \mathrm{C}$ for $5 \mathrm{~min}$, then $15^{\circ} \mathrm{C} \min ^{-1}$ to $250^{\circ} \mathrm{C}$. Injector, EAD outlet, and FID detector temperatures were $260^{\circ} \mathrm{C}$. The column effluent was combined with $\mathrm{N}_{2}$ make-up gas $\left(30 \mathrm{ml} \mathrm{min}^{-1}\right)$ and split 1:1, between the flame ionization detector (FID) and EAD by using a TCD capillary column adapter (Agilent Technology, Wilmington, DE, USA), two deactivated capillary columns (non-polar, $0.25 \mathrm{~mm}$ ID, Alltech) of equal length as transfer lines, and a universal capillary $\mathrm{Y}$ connector (Alltech). The TCD adapter and the $\mathrm{Y}$ connector were connected with a short length of deactivated wide-bore capillary column $(0.53 \mathrm{~mm}$ ID) and a stainless steel reducing union (3.2 $\mathrm{mm}$ OD to $1.6 \mathrm{~mm}$ OD). The end of the column was fixed to the TCD adapter with a regular column nut so that the column was extended to the inside of the wide-bore column to facilitate column changes.

An extra FID port of the GC was modified and used for the EAD outlet. The transfer line passed through the heating block and was protected and insulated with a short length of glass-lined stainless steel tube $(1.6 \mathrm{~mm} \mathrm{OD} \times$ $0.3 \mathrm{~mm}$ ID, Alltech) and a larger diameter stainless steel tube. The transfer line terminated in a humidified, filtered air stream, which was refrigerated by a modified condenser flushed with ice-cold water. The air stream carried the column effluent over the beetle antennal preparation (Robbins et al. 2003). The output signal from the antenna was amplified by a customized single-step high-input impedance DC amplifier. The resulting signal was recorded on an HP 3390A integrator synchronized with the GC integrator. These methods were adapted from Zhang et al. (1997) and Nojima et al. (2003a). Gland extracts from ten virgin females were analyzed using antennae from five different males.

Chemical Analysis Gas chromatography-mass spectrometry (GC-MS) analysis was performed on a Shimadzu QP $5050 \mathrm{~A}$ equipped with a non-polar DB- $1 \mathrm{~ms}$ capillary column $(30 \mathrm{~m} \times 0.25 \mathrm{~mm}$ ID, $0.25 \mu \mathrm{m}$ film thickness; $\mathrm{J} \&$ W Scientific, Folsom, CA, USA) or a polar EC-WAX Econo-Cap capillary column $(30 \mathrm{~m} \times 0.25 \mathrm{~mm}$ ID, $0.25 \mu \mathrm{m}$ film thickness; Alltech), under the same conditions as those in the GC-EAD analyses, except helium was the carrier gas at $1.0 \mathrm{ml} \mathrm{min}^{-1}$. The EAD-active compound was tentatively identified by comparing its mass spectrum to those of compounds in the NIST mass spectral library. Confirmation of the identification was made by comparing GC retention times (on the two columns) and mass spectrum of the beetle-produced product with those of the authentic sample.

Chemicals L-Valine and L-isoleucine methyl esters were supplied by Dr. A.C. Oehlschlager of ChemTica Internacional S.A. (San Jose, Costa Rica).

The D-valine methyl ester was obtained as a hydrochloric acid salt (Aldrich). Dissolving the salt in an aqueous alkali solution and extracting the mixture with three portions of diethyl ether generated the amino acid methyl ester. The ether extracts were combined, washed with brine, dried over sodium sulfate, and concentrated in vacuo. The resulting methyl ester was used without further purification.

Preparation and Field Evaluation of Synthetic Lures Lures were formulated by dissolving the neat compounds in hexane at $20 \mu \mathrm{g} / \mu \mathrm{l}$ and dispensing appropriate amounts in rubber septa (Thomas Scientific, Swedesboro, NJ, USA); the solvent was allowed to evaporate in a fume hood. Lures were deployed in the field in lab-constructed cross-vane traps (Robbins et al. 2006).

Six treatments were tested: L-valine methyl ester at 1, 2, and $4 \mathrm{mg} ; 4 \mathrm{mg}$ L-isoleucine methyl ester; L-valine and L-isoleucine methyl esters at $4 \mathrm{mg}$ each; and a control with hexane applied to the septum. L-Isoleucine methyl ester was included in this field trial because we suspected that it could function as a behavioral antagonist to P. georgiana when combined with L-valine methyl ester. Four replicates of the six treatments were deployed May 19, 2003, around the cranberry bog from which the $P$. georgiana larvae were sampled. The traps were placed about $15 \mathrm{~m}$ apart, with the bottom of the trap about $0.5 \mathrm{~m}$ from the ground. Traps were checked 18 times between May 19 and September 3. Traps were placed randomly at first placement and were rerandomized every other time they were checked. Lures were replaced every 4 weeks. 
Fig. 1 Simultaneous electroantennogram (EAD)-flame ionization detection (FID) traces illustrating male Phyllophaga georgiana antennal responses to a extract of the pheromone gland of a female $P$. georgiana; b $10 \mathrm{ng}$ of L-valine methyl ester; c 10 ng of D-valine methyl ester
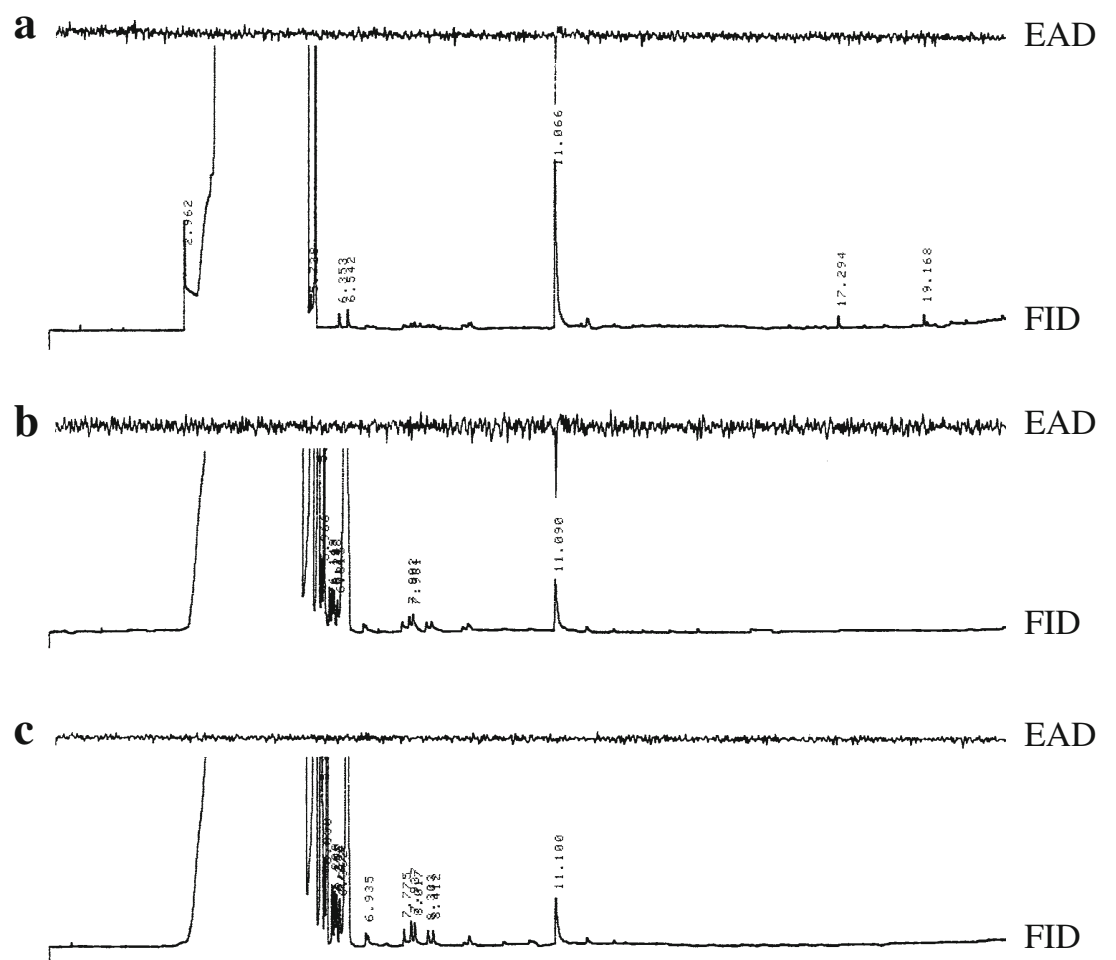

On May 22, 2008, four traps were deployed at each of four cranberry bogs in southern New Jersey to confirm flight phenology for the beetle. Each trap was baited with a septum that contained $4 \mathrm{mg}$ of L-valine methyl ester. The traps were placed at least $100 \mathrm{~m}$ apart, with the bottom about $0.5 \mathrm{~m}$ from the ground. Traps were checked 15 times between May 29 and September 10, and lures were replaced every 4 weeks. Traps were randomized at first placement and re-randomized every other time they were checked.

Captured males were identified to species according to Luginbill and Painter (1953) and Harpootlian (2001).

Statistics The P. georgiana trap catch data were tested for homogeneity of variance using Levene's test and then logtransformed $(x+1)$. Data were analyzed using a one-way ANOVA, $P<0.05$. Fisher's LSD test was used for post hoc comparisons.

\section{Results and Discussion}

Pheromone Identification GC-EAD analysis, using both non-polar and polar columns, of gland extracts of female $P$. georgiana showed one consistent EAD-active compound (Fig. 1a). The mass spectrum of this compound matched that of L-valine methyl ester. GC retention times (on the two columns) compared with those of an authentic sample also confirmed the identification (Fig. 1b). The opposite enantiomer, D-valine methyl ester, did not elicit an EAD response from antennae of male beetles (Fig. 1c). A chiral column was not available at the time of analysis; therefore, we cannot be certain of the chirality of the valine methyl ester. However, based on the relative EAD activities (and field tests; see below), we tentatively assume the Lenantiomer to be the pheromone compound.

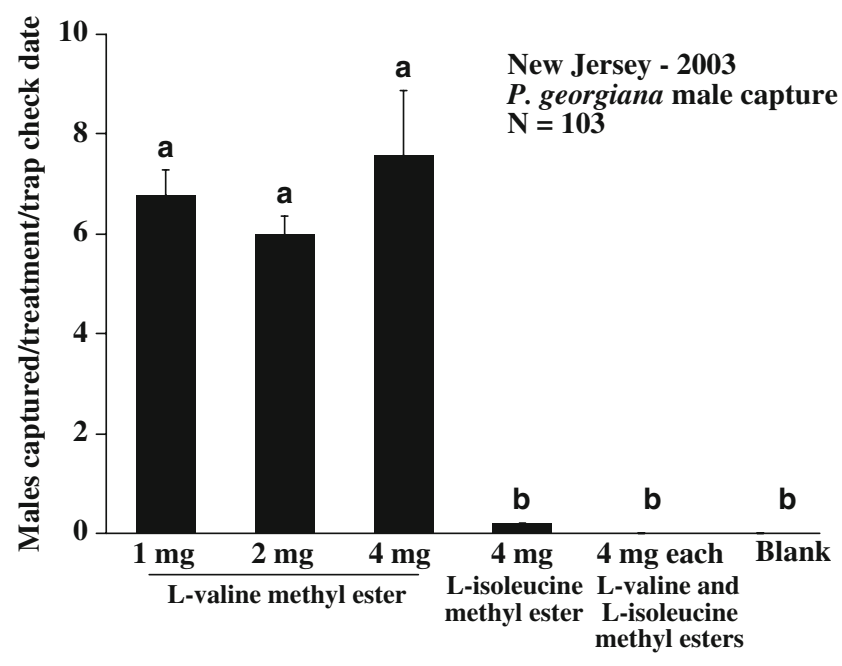

Fig. 2 Average capture/treatment/trap check (mean \pm SE) of male Phyllophaga georgiana in traps baited with various doses of L-valine methyl ester, L-isoleucine methyl ester, and a blend of L-valine/Lisoleucine methyl esters, at Chatsworth, NJ in 2003. Bars with the same letter are not significantly different $(P<0.05$, Fisher's LSD test) 
Fig. 3 Seasonal flight patterns and numbers of males of four species of Phyllophaga caught in pheromone-baited traps near Chatsworth, NJ in 2003
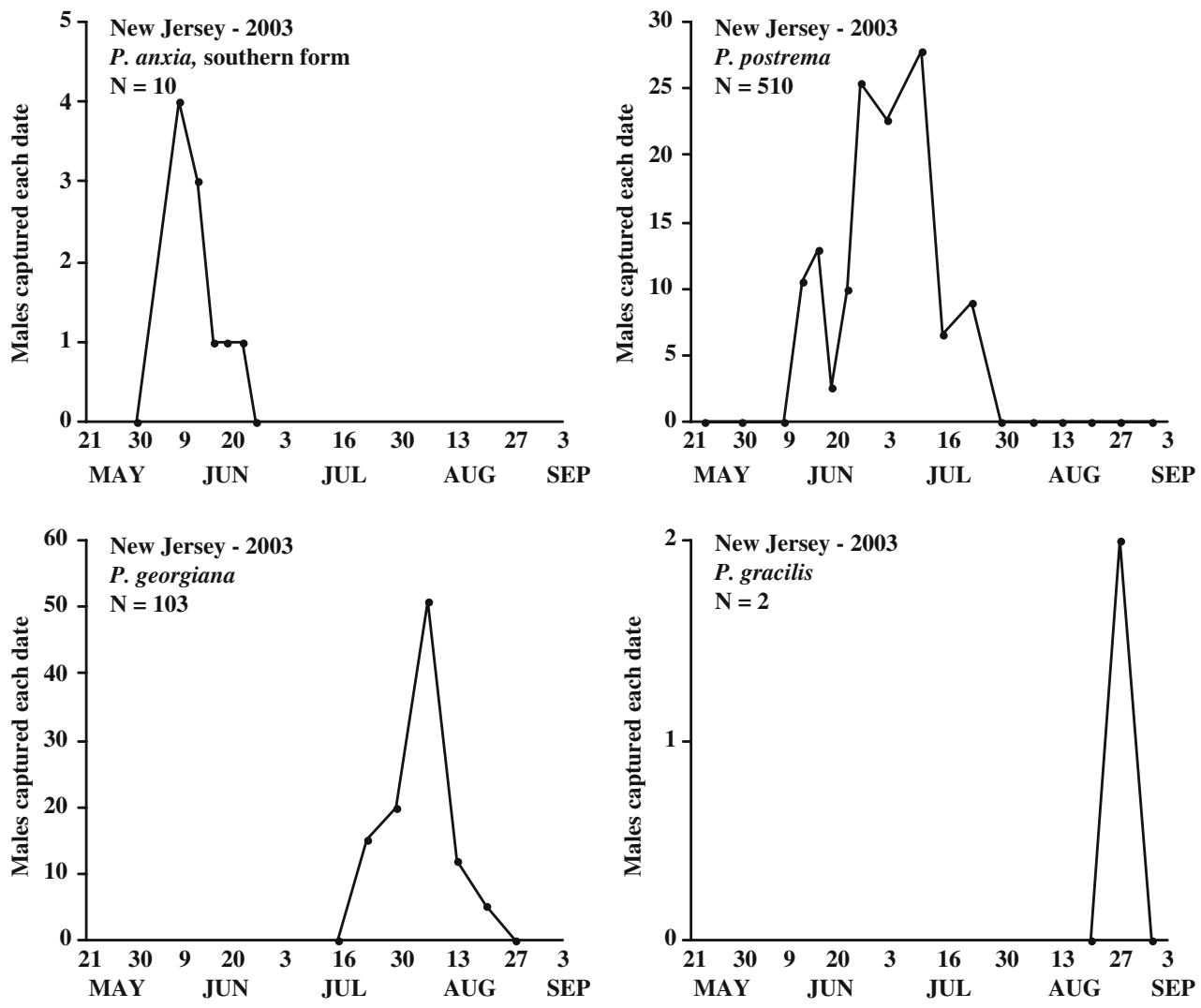

Fig. 4 Seasonal flight patterns and numbers of males of Phyllophaga georgiana captured in pheromone-baited traps at four farms near Chatsworth, NJ in 2008
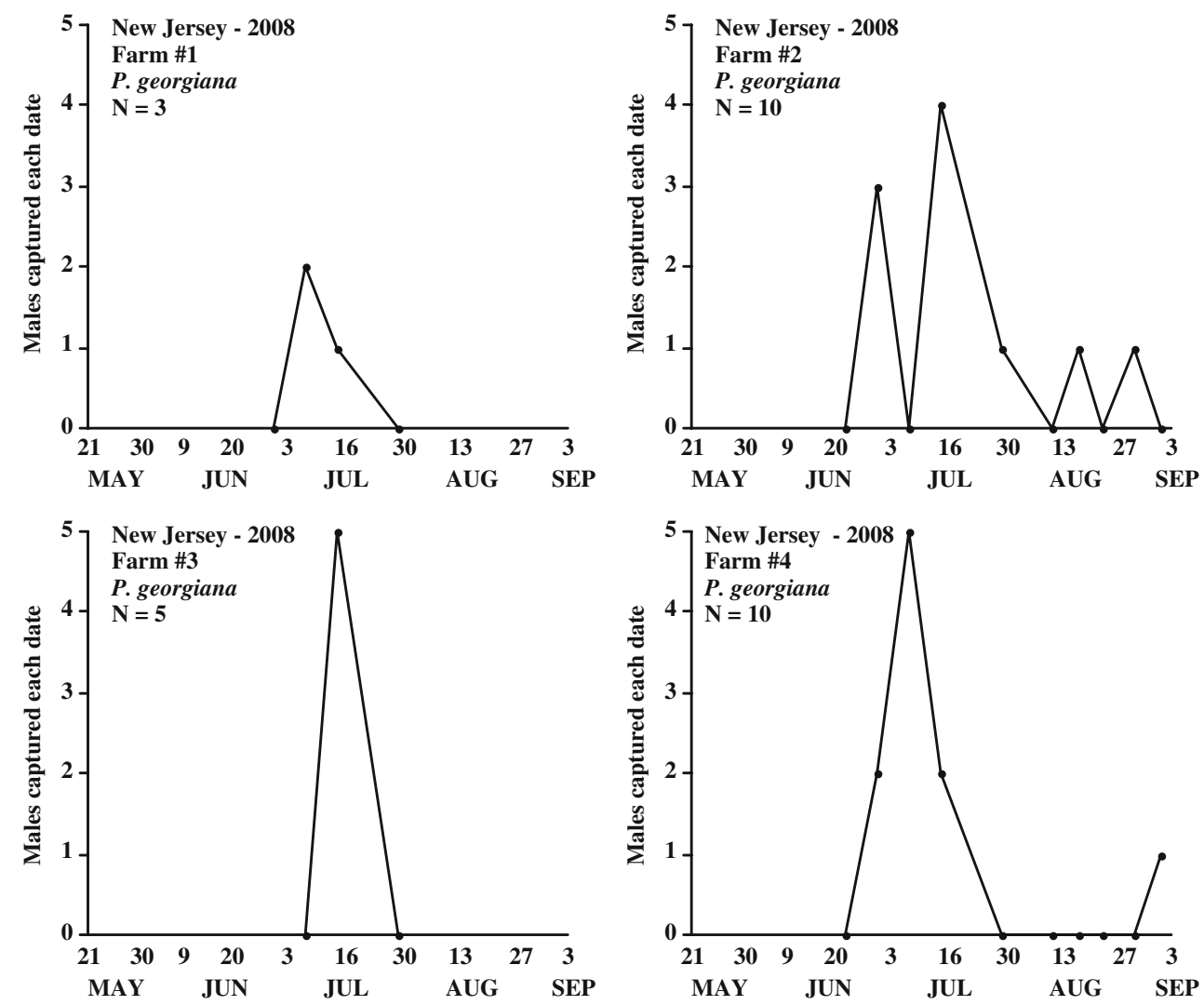
Field Evaluation of Synthetic Lures One-way ANOVA indicated significant differences in $P$. georgiana male captures among the six treatments tested $\left(F_{5,24}=7.70 ; P<\right.$ 0.001 , Fig. 2). Fisher's LSD test in a post hoc comparison showed no significant differences among mean catches of the traps baited with 1,2 , or $4 \mathrm{mg}$ of L-valine methyl ester. However, catches of males in traps baited with any of the three dosages of L-valine methyl ester were significantly greater than catches in traps baited with $4 \mathrm{mg}$ L-isoleucine methyl ester-baited trap, $4 \mathrm{mg}$ each of L-valine and Lisoleucine methyl esters, or the hexane control. A single $P$. georgiana male was captured in a trap baited with $4 \mathrm{mg}$ of L-isoleucine methyl ester, and no males were captured in traps baited with $4 \mathrm{mg}$ each of the methyl esters of L-valine and L-isoleucine, thus indicating that L-isoleucine methyl ester acts as a behavioral antagonist.

Our tentative identification of L-valine methyl ester as the sex pheromone of $P$. georgiana is consistent with previous observations in Tifton, GA in 2000 (Robbins et al. 2006). In that study, two male $P$. georgiana were captured in a trap baited with $4 \mathrm{mg}$ of L-valine methyl ester on two dates in July 2000. The other seven traps at the Tifton location were baited with lures containing varying amounts of L-isoleucine methyl ester, from $10 \%$ to $100 \%$, and no $P$. georgiana were captured in those traps.

Seasonal Flight Patterns for Species Captured Figure 3 illustrates the seasonal flight patterns and numbers of individuals of the four Phyllophaga species captured during the 2003 season. In general, the flight dates and male response to pheromone blends of the species observed in this test corroborate the results reported by Robbins et al. (2006).

Of the ten male $P$. anxia captured in traps baited with Lisoleucine methyl ester, eight were of the southern genitalic form and two were of the northern genitalic form [see Luginbill and Painter (1953) and Woodruff and Beck (1989)]. The southern forms were found on June 9 (four males), June 13 (3), and June 17 (1). The northern forms were found on dates following the flight of the southern forms, namely June 20 (1) and June 24 (1). Further studies may reveal whether the apparent asynchronous flights of the two L-isoleucine methyl ester-responding genitalic forms observed here are consistent over geography and years as well as whether interbreeding occurs in areas of sympatry. See Robbins et al. (2008) for more information regarding pheromone races of the northern and southern genitalic forms of $P$. anxia.

Of the 510 P. postrema captured between mid-June and mid-July, 506 were captured in traps baited with Lisoleucine methyl ester, and four were captured in traps baited with the blend of L-valine and L-isoleucine methyl esters. The two P. gracilis were captured on August 27 in traps baited with L-isoleucine methyl ester.
To date, there have been no studies on the life cycle of $P$. georgiana. However, the fact that the flight does not begin until mid-July suggests that this species probably pupates in the spring, unlike $P$. anxia, which pupates and emerges in the hibernaculum in the fall; the teneral adult remaining underground until the following May or June when the flights begin (Lim et al. 1980). The P. georgiana seasonal flight patterns observed at the four locations where traps were placed during the 2008 season (Fig. 4) were similar to the pattern observed in 2003 (Fig. 3).

Other species in the genus Phyllophaga (s. str.) also have been observed responding to L-valine methyl ester, including $P$. anxia (northern genitalic form, L-valine methyl ester pheromone morph), P. congrua, $P$. crenulata, $P$. hirtiventris, $P$. inversa, $P$. latifrons, $P$. marginalis, and $P$. vehemens (Robbins et al. 2006). Eberhard (1993) reported Phyllophaga males following pheromone upwind to non-conspecific females, landing on the female briefly, and then leaving. Further work should investigate the reproductive isolation of sympatric Phyllophaga species that respond to L-valine methyl ester.

Acknowledgment Thanks to Dong Ho Cha of Cornell University for help with the figures.

\section{References}

EBERHARD, W. G. 1993. Copulatory courtship and morphology of genitalic coupling in seven Phyllophaga species (Coleoptera: Melolonthidae). J. Nat. Hist. 27:683-717.

Evans, A. V., and SMith, A. B. T. 2007. An electronic checklist of the new world chafers (Coleoptera: Scarabaeidae: Melolonthinae) Version 2. <www.museum.unl.edu/research/entomology/nwmelos. $\mathrm{htm}>$.

HARPoOtLIAN, P. J. 2001. Scarab beetles (Coleoptera: Scarabaeidae) of South Carolina. Clemson University Public Service Publishing, Clemson.

Koppenhöfer, A., Rodriguez-SaOna, C., Polavarapu, S., and HoldCRAFT, R. J. 2008. Entomopathogenic nematodes for control of Phyllophaga georgiana (Coleoptera: Scarabaeidae) in cranberries. Biocontrol Sci. Technol. 18:21-31.

Leal, W. S., Sawada, M., Matsuyama, S., Kuwahara, Y., and HASEGAWA, M. 1993. Unusual periodicity of sex pheromone production in the large black chafer Holotrichia parallela. J. Chem. Ecol. 19:1381-1391.

Lim, K. P., Stewart, R. K., and Yule, W. N. 1980. A historical review of the bionomics and control of Phyllophaga anxia (LeConte) (Coleoptera: Scarabaeidae) with special reference to Quebec. Ann. Soc. Entomol. Que. 25:163-178.

LuginBill, P., and PAINTER, H. R. 1953. May beetles of the United States and Canada. United States Department of Agriculture. Tech. Bull. No. 1040.

NoJima, S., LinN, C. E., JR., Morris, B. D., Zhang, A., and RoELOFS, W. L. 2003a. Identification of host fruit volatiles from hawthorn (Crataegus spp.) attractive to hawthorn-origin Rhagoletis pomonella flies. J. Chem. Ecol. 29:319-334. 
Nojima, S., Robbins, P. S., Salsbury, G. A., Morris, B. D., Roelofs, W. L., and Villani, M. G. 2003b. L-leucine methyl ester: the female-produced sex pheromone of the scarab beetle Phyllophaga lanceolata. J. Chem. Ecol. 29:2439-2446.

Robbins, P. S., Crocker, R. L., NoJima, S., Morris, B. D., Roelofs, W. L., and Villani, M. G. 2003. Methyl 2(methylthio)benzoate: the unique sulfur-containing sex pheromone of Phyllophaga crinita. Naturwissen. 90:517-520.

Robbins, P. S., Alm, S. R., Armstrong, C. D., Averill, A. L., BAKER, T. C., BAUERNFIEND, R. J., BAXENDALE, F. P., BRAMAN, S. K., Brandenburg, R. L., Cash, D. B., Couch, G. J., Cowles, R. S., Crocker, R. L., Delamar, Z. D., Dittl, T. G., FitzPatrick, S. M., Flanders, K. L., Forgatsch, T., GibB, T, J., Gill, B. D., Gilrein, D. O., Gorsuch, C. S., Hammond, A. M., Hastings, P. D., Held, D. W., Heller, P. R., Hiskes, R. T., Holliman, J. L., Hudson, W. G., Klein, M. G., KrischiK, V. L., Lee, D. J., Linn, C. E. Jr., Luce, N. J., MacKenzie, K. E., Mannion, C. M., Polavarapu, S., Potter, D. A., Roelofs, W. L., Royals, B. M., Salsbury, G. A., Schiff, N. M., Shetlar,
D. J., Skinner, M., Sparks, B. L., SutscheK, J. A., SutscheK, T. P., Swier, S. R., Sylvia, M. M., Vickers, N. J., VitTum, P. J., Weidman, R. B., Weber, D. C., Williamson, R. C., and VILlani, M. G. 2006. Trapping Phyllophaga spp. (Coleoptera: Scarabaeidae: Melolonthinae) with sex attractants in the United States and Canada. J. Insect Sci. 6:124.

Robbins, P. S., Cash, D. B., Linn, C. E. Jr., and Roelofs, W. L. 2008. Experimental evidence for three pheromone races of the scarab beetle Phyllophaga anxia (LeConte). J. Chem. Ecol. 34:205-214.

WoOdrufF, R. E., and BECK, B. E. 1989. The scarab beetles of Florida (Coleoptera: Scarabaeidae) Part II. The May or June beetles (genus Phyllophaga). Arthropods of Florida and neighboring land areas. Florida Department of Agriculture and Consumer Services. Division of Plant Industry, Gainesville.

Zhang, A., Robbins, P. S., Leal, W. S., LinN, C. E., JR., Villani, M. G., and RoELOFS, W. L. 1997. Essential amino acid methyl esters: major sex pheromone components of the cranberry white grub, Phyllophaga anxia (Coleoptera: Scarabaeidae). J. Chem. Ecol. 23:231-245. 